\title{
316L Stainless Steel Alloys for Orthodontic Application: Effect of Fluorinated Toothpaste on the Corrosion Behavior in Human Saliva
}

\author{
Veaceslav Neaga, Lidia Benea*, Andrada Alexandru \\ Competences Center: Interfaces-Tribocorrosion-Electrochemical Systems, Dunarea de Jos University \\ of Galati, Domnească Street, 47, RO-800008, Galaţi Romania. \\ *E-mail: Lidia.Benea@ugal.ro
}

doi: $10.20964 / 2020.10 .17$

Received: 1 May 2020 / Accepted: 7 July 2020 / Published: 31 August 2020

\begin{abstract}
Orthodontic implanted wires are made of different stainless steels, to regulate the teeth. The fluorinated toothpastes used during the period of the treatment may induce a corrosive effect on these stainless steels. Hence, the main objective of this research work is to investigate and evaluate the effect of fluorinated toothpaste on the corrosion behavior of $316 \mathrm{~L}$ stainless steel in Carter-Brugirard human saliva. Electrochemical methods such: Open circuit potential, potentiodynamic polarization and electrochemical impedance spectroscopy; have been used to evaluate the corrosion behavior of stainless steel in saliva and saliva mixed with fluorinated toothpaste. The OCP value recorded for 316L SS immersed in saliva mixed with fluorinated toothpaste was lower than 316L SS in saliva without fluorinated toothpaste. This behavior confirms a high reactivity of 316L SS in presence of fluorinated toothpaste. Electrochemical impedance spectroscopy (EIS) results indicate a decreasing trend in specific polarization resistance of stainless steel 316L in presence of fluorinated toothpaste. The results show that the addition of a small quantity of fluorinated toothpaste in Carter-Brugirard human saliva affects the corrosion resistance of $316 \mathrm{~L}$ stainless steel.
\end{abstract}

Keywords: Orthodontic applications, toothpaste, stainless steel, corrosion, human saliva, electrochemical impedance spectroscopy.

\section{$\underline{\text { FULL TEXT }}$}

(C) 2020 The Authors. Published by ESG (www.electrochemsci.org). This article is an open access article distributed under the terms and conditions of the Creative Commons Attribution license (http://creativecommons.org/licenses/by/4.0/). 